\section{Diet and Congenital Defects}

SIR,-In replying to your leading article (23 December, p. 684) I address those of your readers who recognize that a hypothesis concerning abatement is rarely transcribable directly into one of cause; and who notice also that the "potato blight hypothesis" you speak of has not been proposed-at least by me. Most of the evidence for the potatoavoidance hypothesis for the prevention, in the U.K., of $95 \%$ of spina bifida and anencephaly does indeed come from blight, that being one of the best-recorded and most important potato diseases. But the potato, like man, is subject to many diseases, perhaps several being capable of eliciting a phytoalexin (antibiotic) response, which in most plants is relatively non-specific, as it apparently is in the potato. ${ }^{1}$

The year-to-year relationships between blight epidemics and epidemics of anencephaly and spina bifida have been clearly shown not to be due to chance. $2-4$ Correlations with blight in West Scotland are easily detectable, despite the confounding effect expected from potatoes from the east. One cannot render such correlations meaningless by saying (as you, Sir, seem to be doing) that one would expect them to have been obscured by such a confounding factor. The year-to-year relationship was accurately predicted from the geographical and seasonal relationships between anencephaly and spina bifida and potato quality and from the biochemistry of potatoes in storage, so it is likely that the true explanation does involve the potato.

Discussion can be extended beyond Scotland. We can observe a fulfilment of the same year-to-year prediction in the national figures for England and Wales. These are now summarized for anencephaly ${ }^{5}$ over a recent period in the $1960 \mathrm{~s}$, a period for which there are estimates available, on a national basis, of the incidence of tuber blight $t^{6}$ just before harvesting. The data are from crop check weighings of over 1,000 fields each year. The incidence of anencephaly among still and live births fell by about 0.06 per 1,000 per annum over this period, and this may well reflect the known increase in the provision of temperature-controlled storage for potatoes. The proportion of tubers blighted showed no obvious trend over these particular years despite an intensification of blight control measures which, subsequently, have proved effective in limiting tuber blight. We would predict the incidence of blight in one season to be related to that of anencephaly for the following calendar year (shifted by six weeks to begin and end at mid-February). The effect of a season's blight shows in the anencephalic births over a 12-month period, which reach a peak incidence rate at about Christmas. Modal gestation time for anencephalic pregnancies is 33 weeks and the Christmas peak presumably reflects that mode. Some anencephalic pregnancies are, however, carried to term or beyond, so the end of the 12-month period has been chosen in mid-February (11 years after the end of the calendar year of the relevant blight season). Since terato- genesis probably occurs in the first month of pregnancy, the date of the peak incidence points to maximal teratogenicity in May. In that month the over-wintered potatoes are at their worst quality.

The weighted means of the anencephaly rates over the four quarters of a year (after the rate for the first quarter has been averaged with the rate for the first quarter of the next following year) are 2.048, 1.994, $1.989,1.875,1.860,1.778,1.688,1.718$ per 1,000 for 1962-9. After adjustment, without change of mean, for a trend of -0.06 per 1,000 per year, these rates are given below for year $Y+1 \frac{1}{8}$, together with the percentage (by weight) of tubers that were visibly blighted at time of harvest in year $\mathbf{Y}$ (see table). The observed correlation coefficient $(r)$ is $+0.87 . P=0.005$. These blights and births (from totals of 700,000 per annum or more) show a positive correlation. This is even more clearly seen in the figure.

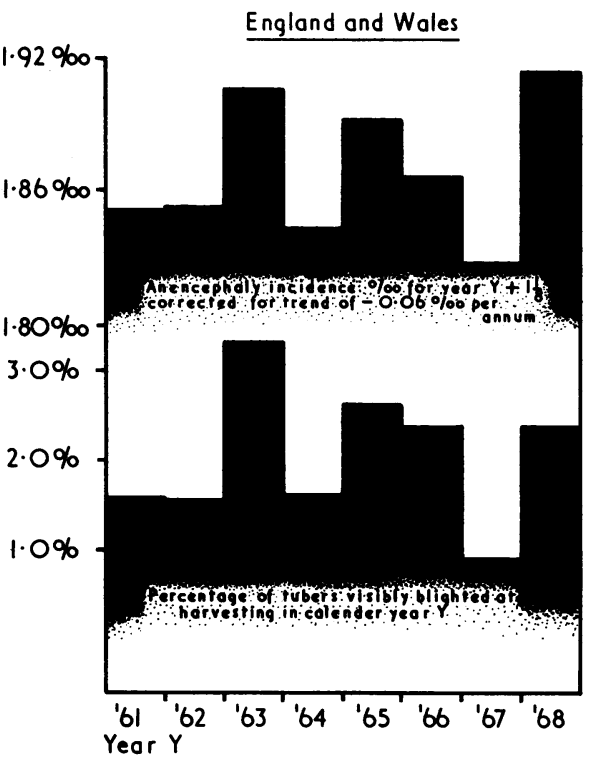

I should like to assume, Sir, that you would have written your leading article with a rather different emphasis had you known of this further verification of the year-toyear prediction. On this assumption I propose not to clarify here your doubts and confusions. Many are already satisfactorily dealt with elsewhere $e^{2-4} 7-9$ and others soon will be. ${ }^{10}$

The potato effect was largely missed by Professor Knox's computer. ${ }^{5}$ This was chiefly, I believe, because the computer was not well informed about some simple properties of potatoes, such as their liability to disease and to deterioration on storage. The consumption of potatoes, by season, is positively correlated with good quality (both being high in the autumn and low after winter storage) or, in other words, negatively correlated with poor quality. The negative correlation (seasonal) that was found between potato consumption and anencephaly 5 could therefore reflect the existence of a positive correlation between poor quality and anencephaly, just as we expect on the hypothesis. The key variable, again, is potato quality, which here overrides quantity.

A controlled clinical trial of potato avoidance is now needed to test the potato claim definitively and to estimate the proportions of the potato-insensitive residuum directly, at least in England and Wales. The study being run by Dr. J. Lorber (6 January, p. 46) without any controls will serve a similar purpose but less convincingly. His propositi will be mainly spina bifida babies, ours will be mainly anencephaly babies, and there will be other differences in the designs of the trials that should minimize the risk of serious overlapping. Despite Dr. K. M. Laurence's arguments ${ }^{11}$ (6 January, p. 46), also voiced by $\mathrm{Dr}$. Lorber, I believe that sufficient differences will remain between the potato diets in the test and control groups for controls to be useful to verify the hypothesis.-I am, etc.

JAMES H. ReNWICK London School of Hygiene and Tropical Medicine, London W.C.1

1 Lyon, G., Physiological Plant Pathology, 1972, 2 Renwick, J. H., British fournal of Preventive and Social Medicine, 1972, 26, 67, and (errata) 269. 3 Renwick, J. H., New Scientist, 1972, 56, 277. 5 Renwick, J. H., Lancet, 1972, 2, 336 and 967. (1972, 26, 219 and unpublished. Social Medicine, 1972, 26, 219 and unpublished. Ptatistics, 1972. London: Potato Marketing Board and unpublished.

7 Renwick, J. H., New Society, 1972, 22, 212.

8 Renwick, J. H., The Guardian, 1972, 6 December, p. 12 .

Renwick, J H. Lancet, 1973, 96.

Renwick, J. H. H., General Practitioner, 1973. Letter to the Bditor In

11 Letrence, K. M., Nature, 1972, 240, 579.

\section{Surface Particles on Leukaemic Lymphocytes}

SIR,-In the past few years a number of leading articles on the aetiology of cancer, and in particular of human leukaemia, have inclined to attribute a positive role to viruses, though despite extensive studies there has been no real evidence to support this.

In recent experiments here lymphocytes from children with measles during a rash were being examined in the electron microscope to visualize measle nucleoprotein tubules in the lymphocytes. I happened to use leukaemic lymphocytes from five cases of chronic lymphatic leukaemia and one of acute leukaemia as controls against measles. In all cases lymphocytes were separated as described by Hughes and Caspary, ${ }^{1}$ the procedure taking about two-and-a-half hours. Lymphocytes were fixed then blocked in epon.

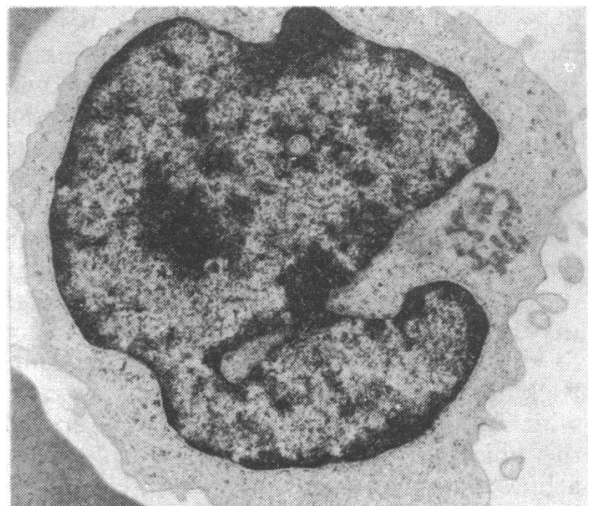

FIG. 1-Lymphocyte from child on second day of $(x \mathbf{8 , 4 1 0})$

\begin{tabular}{c|c|c|c|c|c|c|c|c}
\hline Year Y (tubers) & 1961 & 1962 & 1963 & 1964 & 1965 & 1966 & 1967 & 1968 \\
\hline $\begin{array}{c}\text { Proportion (by weight) of tubers } \\
\text { visibly blighted in year Y } \\
\text { Incidence of anencephaly per 1.000 } \\
\text { in the 12-month period Y }\end{array}$ & $1.54 \%$ & $1.52 \%$ & $3.33 \%$ & $1.58 \%$ & $2.64 \%$ & $2.36 \%$ & $0.90 \%$ & $2.34 \%$ \\
(corrected for trend) .. & 1.853 & 1.854 & 1.904 & 1.845 & 1.890 & 1.863 & 1.828 & 1.913 \\
\hline
\end{tabular}


Lymphocytes from children on the second day of the rash showed typical measle nucleoprotein tubules (fig. 1). These tubules were not seen in leukaemic lymphocytes. On the other hand, leukaemic lymphocytes showed membrane blebs on the surface (fig. 2) and besides these blebs particles were

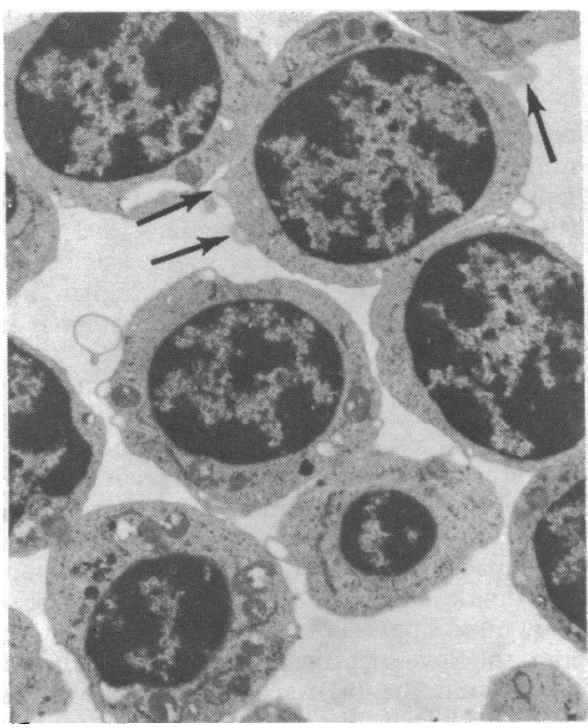

FIG. 2-Lymphocytes from a leukaemic patient. Note particles budding (arrowed) (x 4,625).

seen in various stages of budding from the surface of the lymphocytes (fig. 3A). These particles had an internal core of abou $320 \mathrm{~nm}$. The particles had a typical virus morphology with three concentric layers (fig. 3B). The size of the particles found in

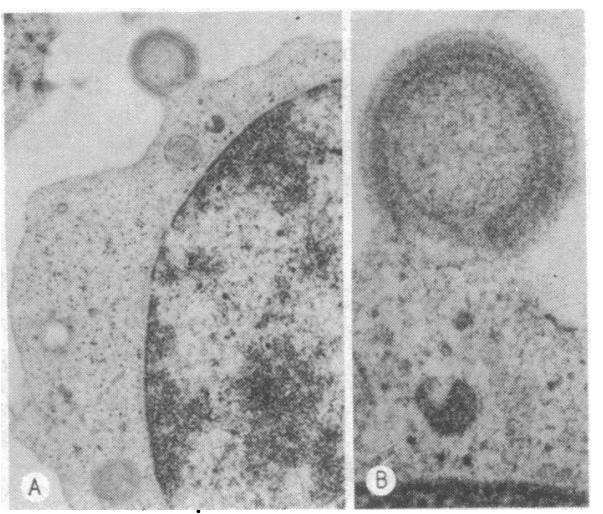

FIG. 3-A. Lymphocyte from another leukaemic patient showing virus-like particles budding from the surface (x 14,690).

B. High-power view of budding particle. Note three relatively electron-dense coats with radial striation (x 48,970).

leukaemic patients was similar to that of the paramyxovirus group, but there was no evidence of internal nucleoprotein tubules.

According to the size, these particles do not appear to be virus and, on the ground of morphology, they do not appear to be mycoplasma. Though these results are repeatable their relationship to disease cannot be inferred at this stage.-I am, etc.,

Demyelinating Diseases Unit,
Medical Research Council,

H. K. NARANG

Newcastle General Hospital,

Newcastle upon Tyne 1 Hughes, D., and Caspary, E. A., Intemational

\section{Idiopathic Gangrene in African Adults}

SIR,-In recent times an explanation for the idiopathic gangrene of African adults has been sought in a disturbance of fibrinolysis, as exemplified by the paper by Dr. R. D. Barr and others (4 November, p. 273). These cases are as plentiful in Pretoria as they appear to be elsewhere in Africa. Over the past few years, however, we have become convinced that the mystery could be partly cleared up if the skin rash which accompanies the gangrene in a proportion of cases were correctly interpreted. The skin eruption in question is a papulonecrotic tuberculid. The acute arterial episode coincides with attacks of the skin eruption in a sufficient number of cases to indicate an important association. The skin lesion is also of a vascular, infarcting type, though the changes are on a small scale.

Papulonecrotic tuberculids have become rare in Europe, and many may feel diffident in making the diagnosis. However, in Africa one should take particular notice of rather unimpressive-looking eruptive follicular papules and pustules with a tendency to necrosis and pock-like scar formation. These may appear anywhere on the limbs, but are often gathered somewhat more closely together over the extensor surfaces of joints. The face, pinnae, and eyes (phlyctenulae) are also liable to show the lesions. A strongly positive tuberculin reaction, a lymph node focus, sometimes containing the human strain of Mycobacterium tuberculosis, and prompt response to antituberculosis treatment will support the relationship. Histological examination of the papulonecrotic skin lesions, when performed by the general pa'hologist, yields little help.

Not much has been written about allergic vascular lesions in the subcutaneous arteries in tuberculosis. Nevertheless, there seems to be enough certainty about it for us to recommend strongly that cases elsewhore in Africa be examined with this possibility in mind. It will be interesting to learn if the unquestionably tuberculous cases also show prolonged lysis times, and how the skin and subcutaneous sites of vasculitis may compare with one another in the same case.-We are, etc.,

G. H. Findi.AY Department of Dermatology, J. G. L. MORRISON

Pretoria, South Africa

\section{Disseminating Cysticercosis in England}

SIR,- We would like to bring to your notice the following case of cysticercosis cellulosae which occurred recently in this country.

On 31 August 1972 a male Hin ${ }^{\lambda} u$, aged 33 vears, born in India but resident in Grea Britain for the past $8 \frac{1}{2}$ years, was seen in the outpatient department. He had not returned to India since first arriving here and had no been abroad. He gave a history that he had had a dry cough six months previously lasting six weeks. As the cough improved he became aware of frontal headaches associated wth pyrexia; investigations at the local chest clinic failed to reveal the cause of these symotoms. He was symptom-free for about two months. when his drv cough recurred and this was followed by a bout of sweating. rigors, headache, and pyrexia of $101-102^{\circ} \mathrm{F}$ lastino three davs. A week late he was referred to the outpatient department.

On examination nothing was found abnormal clinically. The following investigations were carried out: Hb $94 \%$, E.S.R. $20 \mathrm{~mm}$ in $1 \mathrm{hr}$,
W.B.C. $4,600 / \mathrm{mm}^{3}$, neutrophils $66 \%$, lymphocytes $33 \%$, monocytes $1 \%$, serum albumin 4.4 $\mathrm{g} / 100 \mathrm{ml}$, globulin $4.9 \mathrm{~g} / 100 \mathrm{ml}$, total proteins $9.3 \mathrm{~g} / 100 \mathrm{ml}$, Bilirubin $<1 \mathrm{mg} / 100 \mathrm{ml}$, alkaline phosphatase 15 K.A. units $/ 100 \mathrm{ml}$, thymol turbidity 3 units. Electrophoresis showed a slight diffuse increase in the gamma band and a slight increase of alpha-2 globulin, suggestive of a collagen disease.

On his second attendance at outpatients two weeks later a small, subcutaneous, freely movable, non-tender lump about the size of a hazel nut was discovered just below the right clavicle. On biopsy this was reported by Dr. W. R Richards to be Cysticercus cellulosae, the intermediate stage of Taenia solium. The finding was confirmed by Professor G. S. Nelson of the London School of Hygiene and Tropical Medicine. $X$-rays of the patient's whole body failed to show evidence of calcification.

On his third outpatient attendance, after a further two weeks, six further subcutanecus nodules had appeared. He was admitted to hospital and starved for 72 hours; a Rehfuss tube was then passed to the duodenum and he was given $1 \mathrm{~g}$ of mepacrine dissolved in $40 \mathrm{ml}$ of water, followed half an hour later by a saline purge. All his stools were collected, but no tapeworms or segments were passed.

The history of recent episodes of headache, severe sweating, shivering, and pyrexia would correspond to the generalized disseminating invasive stage of the infestation and this was confirmed by biopsy. Infestation may have resulted from (1) autoinfection in a subject already infested with $T$. solium, or (2) infection from some other person carrying $T$. solium, excreting the eggs, and contaminating food. The recent onset of the symptoms suggests that the infection was not acquired in India. As a Hindu, he denies ever eating pork in India. We failed to find evidence of intestinal infestation with $T$. solium now and thus of autoinfection The evidence points to the infection having been acquired in this country, either from a carrier of $T$. solium or by eating infected pork. The patient admits to eating pork in the canteen at his place of work, but nowhere else. He lives alone with his wife, who is well and symptomless.

This case is reported from the point of view of the rareness of the condition in this country at the present time and of the exceptional rarity of observing a patient during the dissemination of the cysticercus in the body.

We are grateful to Professor G. S. Nelson for confirming the biopsy reports.-We are, etc.,

\section{R. WYBURN-MASON} M. A. SHATKR

Hounslow Hospital, Middlesex

\section{Children's Wheelchair Clinic}

SIR,-The experiences of Dr. K. S. Holt and others (16 December, p. 651) in running a handicapped children's wheelchair clinic at the Wolfson Centre are very similar to those encountered in other centres. Many children are failing to progress or are regressing because the expensive apparatus provided is inappropriate, improperly adjusted, or used incorrectly. The co-operation between the disciplines which Dr. Holt has achieved is a step towards surmounting some of these problems, but the training of doctors, phvsiotherapists, and other workers and the wider dissemination of information on available appliances will go only part of the way to improving the situation. 